\title{
Çevrenin Restoratif Kalitesinin Ölçümü: Algılanan Restoratiflik Ölçeğinin Türkçeye Uyarlanması
}

\author{
İrem Özçifçi ${ }^{1}$, Işı1 Kaymaz ${ }^{2 *}$, İlkden Tazebay ${ }^{3}$, Ferhan Elmalı ${ }^{4}$ \\ ${ }^{1}$ Ankara Üniversitesi, Ziraat Fakültesi, Peyzaj Mimarlı̆̆ı Bölümü, Ankara, Türkiye, (ORCID: 0000-0002-7095-012X), irmkync@gmail.com \\ 2* Ankara Üniversitesi, Ziraat Fakültesi, Peyzaj Mimarlığı Bölümü, Ankara, Türkiye (ORCID: 0000-0002-2659-4965), cakci@agri.ankara.edu.tr \\ ${ }^{3}$ Ankara Üniversitesi, Ziraat Fakültesi, Peyzaj Mimarlı̆̆ı Bölümü, Ankara, Türkiye (ORCID: 0000-0002-8286-6574), tazebay@ ankara.edu.tr \\ ${ }^{4}$ İzmir Katip Çelebi Üniversitesi, Tıp Fakültesi, Temel Tip Bilimleri Bölümü, İzmir, Türkiye (ORCID: 0000-0002-1967-1811), ferhan.elmali@ ikcu.edu.tr
}

(İlk Geliş Tarihi 23 Ocak 2021 ve Kabul Tarihi 28 Mart 2021)

(DOI: $10.31590 /$ ejosat.867180)

ATIF/REFERENCE: Özçifçi, İ., Kaymaz, I., Tazebay, İ. \& Elmalı, F. (2021). Çevrenin Restoratif Kalitesinin Ölçümü: Algılanan Restoratiflik Ölçeğinin Türkçeye Uyarlanması. Avrupa Bilim ve Teknoloji Dergisi, (23), 288-295.

\section{$\ddot{O} \mathbf{z}$}

Özellikle bireylerin çevre kaynaklı yoğun zihinsel bilgiye maruz kaldıkları kentsel alanlarda, çevrenin restoratif kalitesini zenginleştirecek tasarım müdahaleleri iyi oluş hali açısından önem taşımaktadır. Bu çalışma kapsamında 1997 yılında Hartig, Korpela, Evans ve Gärling tarafından geliştirilen Algılanan Restoratiflik Ölçeğinin (ARÖ) Türkçeye uyarlanarak, mekânsal tasarım çalışmalarında kullanılacak bir ölçme aracının alanyazına kazandırılması hedeflenmiştir. Araştırma, peyzaj mimarlığı bölümlerinde eğitim gören 279 lisans öğrencisi ile farklı restoratiflik düzeyinde kategorize edilmiş 9 adet fotoğraf kullanılarak gerçekleştirilmiştir. Ölçeğin kapsam geçerliliği için "Aiken V Formulasyonu" kullanılmıştır. Uyarlanan ölçeğin yapı geçerliğini belirlemek amacıyla yapılan doğrulayıcı faktör analizi sonucunda 26 maddeden ve 4 boyuttan oluşan modelin iyi uyum verdiği bulunmuştur $[\chi 2(288, N=$ $279)=746.67, \chi 2 / \mathrm{sd}=2.59, \mathrm{SRMR}=.075, \mathrm{CFI}=.91, \mathrm{RMSEA}=.075]$. Cronbach alfa iç tutarlllık katsayısı alt boyutlar için $.84-.90$ arasında bulunuştur. Sonuç olarak, bu çalışma ARÖ'nün Türkçe formunun geçerli ve güvenilir bir araç olarak kullanılabileceğini göstermiştir.

\section{Measurement of Environmental Restorativeness Quality: Adaptation of "Perceived Restorativeness Scale" Into Turkish}

\begin{abstract}
Design interventions aimed at enhancing the environment's restorative quality is crucial to well-being, especially in urban environments where individuals are exposed to overwhelming information derived from the physcial environment. The aim of this study is to adapt Perceived Restorativeness Scale -which was developed by Hartig, Korpela, Evans \& Gärling in 1997 - to Turkish language to develop a tool to be used in spatial design. The study was carried out with 279 undergraduate landscape architecture students, using 9 colored slides categorized into different restorative levels. "Aiken's V Formula" was used. Confirmatory factor analysis revealed that the model consisting of 26 items and 4 dimensions fit well $[\chi 2(288, \mathrm{~N}=279)=746.67, \chi 2 / \mathrm{sd}=2.59$, $\mathrm{SRMR}=.075, \mathrm{CFI}=.91$, RMSEA=.075]. The Cronbach's alpha values for the subscales were .84-.90. Consequently, this study has showed that Turkish version of the PRS can be used as a valid and reliable instrument.
\end{abstract}

Keywords: Spatial design, Perceived Restorativeness Scale, Mental Restoration, Environmental Quality.

\footnotetext{
*Sorumlu Yazar: cakci@agri.ankara.edu.tr
} 


\section{Giriş}

Modern toplumda insanın fiziksel çevresi ile olan etkileşiminin yine insanın sağlığı ve iyi olma hali ile ilişkili olduğu anlayışı giderek daha fazla kabul görmekte ve bu doğrultuda farklı çalışma alanları (coğrafya, peyzaj mimarlığı, çevre psikolojisi vb.) tarafından da bu konu ilgi görmektedir. Kentleşme, günümüzün fiziksel çevresini biçimlendiren önemli bir olgudur. Birleşmiş Milletler verilerine göre 1950'de 751 milyon olan kentsel nüfus 2018 yılında 4.2 milyara ulaşmıştır (BM, 2018). Her ne kadar kentler daha iyi sağlı sistemleri, iş ve eğitim imkânları gibi yaşam kalitesini arttırmaya yönelik olanaklar sağlayan ortamlar olsa da, insan sağlığı açısından riskler de barındırmaktadırlar (Bai ve ark.,2012; DSÖ, 2017; Renalds ve ark., 2010). Kentsel ortamdaki kirleticilere (hava kirliliği, gürültü, su kirliliği) maruz kalmanın yanı sıra hatalı kent planlamanın, sürdürülebilir olmayan kentsel çevre yönetiminin ve sosyo-ekonomik çevre koşulları ile hizmetlere erişimde toplumsal eşitsizliklerin de anksiyete, depresyon, dikkat eksikliği bozukluğu, madde kullanımı, saldırgan davranışlar, obezite, kardiyovasküler hastalıklar, solunum ve bağışıklık sistemi rahatsızlıkları ilişkili olduğu alanyazında gösterilmiştir (Srinivasan ve ark.,2003).

Diğer yandan, sosyal bilimlerin insan sağlığı ve doğal alanlar arasındaki karmaşık iliş̧inin araştırılmasına yönelik ilgisi, yapılı çevrenin sağlık ve iyi oluş hali üzerindeki etkilerine karşı farklı bakış açılarının gelişmesine yardımcı olmuştur. 1960'lı yıllarda davranışçı yaklaşımla başlayan birey ve çevresi arasındaki uyumun irdelenmesine yönelik çalışmaları (örneğin French ve ark., 1974; Pervin, 1968) insan-çevre ilişkisini bilişsel süreçleri temel alarak inceleyen çalışmalar izlemiştir (örneğin Kaplan R. ve Kaplan S., 1989; Kaplan, 1983).

Bilgi, insanın evrimsel süreci boyunca yaşamını devam ettirebilmesi adına oldukça önemli bir olgudur ve fiziksel çevre barındırdığı ögeler ve bu ögelerin kompozisyonu ile ilişkili olarak farklı biçimlerde bilgi sunar (Kaplan ve ark., 1998). Bununla birlikte bu bilginin değerlendirilmesi, bilgiye tepki verilmesi, bilginin çok fazla olması ve insanın bu bilgiyi özümseme ve sentezleme kapasitesini zaman zaman aşması nedeni ile oldukça karmaşık bir süreçtir (Gibson, 1979). Bu süreçte dikkat ve güç sarf etmek gerekirken, insanın yönlendirilmiş dikkat kapasitesi kısıtlıdır (Kaplan ve ark., 1998). Fiziksel çevre, çoğu zaman, bireyin bilişsel işlevselliğini destekler özellikte olmadığından, bireyler çevre ile uyumluluğun eksikliğine bağlı kaybettikleri psikolojik kaynaklarını restorasyona, bir başka deyişle yenilemeye yönelik olanaklar ararlar (Kaplan, 1983). Dikkat kapasitesinin aşılması ile ortaya çıkan stres, obezite, performans düşüklüğü ve dikkat yorgunluğu gibi olumsuz durumlara karşılık restoratif deneyimler olumlu ruh hali değişikliği, yönlendirilmiş dikkat kapasitesinin yenilenmesi gibi olumlu etkiler yaratabilmektedir (Hartig ve ark., 1997; Kaplan, 1983, Korpela ve ark., 2001; Ohly ve ark., 2016: 305; Ulrich ve ark, 1991). Restoratif deneyim ve restoratif çevre kavramları, yönlendirilmiş dikkat yorgunluğunu azaltan olanaklar olarak tanımlanabilir (Kaplan R. ve Kaplan S., 1989).

Evrimsel psikoloji kuramlarından yola çıkarak, doğal ortamların en etkin restoratif deneyimi sağladıklarını öne süren bir çok çalışma (örneğin Kaplan, 2001; Kaplan R. ve Kaplan S., 1989; Kaplan ve Talbot, 1983; Parsons, 1991; Ulrich, 1981; Ulrich, 1984; Ulrich ve ark., 1991) bulunmakla birlikte restoratif deneyimlere ilişkin alanyazında iki temel kuram bulunmaktadır;
Ulrich ve ark. (1991) tarafindan geliştirilen "Stres Azaltma Kuramı" ve Kaplan (1995) tarafından geliştirilen "Dikkat Restorasyonu Kuramı”. Ulrich ve ark. (1991) stres seviyesini arttıran bir video sonrası katılımcılara doğal ve kentsel alanlara ilişkin renkli ve sesli görüntüler izletmişler; doğal görüntüleri izleyen katılımcılarda fizyolojik ve sözel ölçümler sonrası stres seviyesindeki iyileşmenin daha fazla olduğunu tespit etmişlerdir. Stres Azaltma Kuramı, bireylerin restorasyon kaynağ doğaya verdikleri anlık duygusal tepkilere dayanırken Kaplan (1995) tarafindan geliştirilen Dikkat Restorasyonu Kuramı ise doğal çevrelerle olan iletişimden elde edilebilecek potansiyel bilişsel faydalara odaklanmaktadır (Joye ve Dewitte, 2018). Bu kurama göre restoratif çevrenin dört temel özelliği bulunmaktadır; (i) günlük yaşamın neden olduğu stresten uzaklaşabilmeye fursat tanır (being away), (ii) yönlendirilmiş dikkat gerektirmeyen olay desenlerini barındırarak zihinsel dinlenme sağlar (fascination), (iii) dikkati dağıtmayacak kapsam ve uyuma sahiptir (extent) ve (iv) bireyin işlevselliğini gereğinden fazla dikkat ve güç gerektirmeden destekleyebilir (compatibility) (Kaplan, 1995). Kaplan (1995) yine aynı çalışmasında doğal alanların yapılı çevrelere göre bu özelliklere daha fazla sahip olduğunu belirtmektedir. Bu çalışmalarda doğal çevrelerden kasıt her zaman için kentsel olmayan alanlar olmayıp, özellikle vejetasyonun baskın olduğu yeşil alanları da kapsamaktadır (Kaplan ve ark., 1998).

Kentsel alanlarda yaşayan bireyler sürekli olarak fazla miktarda dikkat gerektiren uyaranlara ve sonuç olarak da daha fazla zihinsel yorgunluğa maruz kalmaktadır (Peschardt ve Stigsdotter, 2013). Kentsel kamusal alanlarda, yapısal ve doğal elemanların uygun kompozisyonlarda kullanımıyla restoratif olanaklar tanıyan mekânlar yaratılması bu anlamda önem kazanmaktadır. Mekânsal tasarım kapsamında doğanın iyileştirici etkilerinin ele alınması, aslında yeni değildir. Peyzaj mimarı Frederick Law Olmsted, 1865 'te kentlerin ve kentlilerin iş bulma taleplerinin stresle olan ilişkisini vurgulayarak, bu tip stres kaynaklarına karşı doğayı deneyimlemenin restorasyona ve iyileşmeye katkıda bulunduğunu yazmıştır (Ulrich ve ark., 1991). Olmsted'e göre doğal alanlarda zihinsel çaba en az düzeydedir ve bu nedenle restoratif özellikleri yüksektir (Ulrich ve ark., 1991, s.206). Nitekim Olmsted, bu yaklaşımını New York'taki Central Park örneğinde olduğu gibi kent park1 tasarımlarına pastoral bir anlayışla yansıtmıştır. Olmsted'in bu sezgisel yaklaşımına karşılık, restoratif özellikleri yüksek mekânlar yaratılması için ise çevre psikolojisi alanındaki çalışmaları işlevselleştirecek araçlar gerekmektedir. Bu amaçla; Hartig ve ark. (1996, 1997) tarafindan, Kaplan'ın Dikkat Restorasyonu Kuramı temel alınarak, "Algılanan Restoratiflik Ölçeği” (ARÖ) geliştirilmiştir. Ölçeğin geliştirilmesinde Dikkat Restorasyonu Kuramı çerçevesinde ele alınan ve daha önce değinilen restoratif çevrelerin temel dört özelliğini temsiliyeti ((i) uzaklaşma, (ii) dikkat gerektirmeyen olay desenlerini barındırma, (iii) uygun kapsam ve uyum ve (iv) bireyin işlevselliği ile uyumluluk) ve restoratif potansiyeli farklılık gösteren fiziksel çevrelerin ayrımının ortaya koyulması hedeflenmiştir. Geliştirilmesini takip eden yıllarda, ölçek üzerinde, farklı araştırmacılar tarafından kısaltmalar ve kapsam değişiklikleri yapılmış olsa da (Rennit ve Maikov, 2015) ARÖ çok sayıda çalışmada kullanılmakta, dolayısıyla geçerliği yüksek olarak kabul edilmektedir (Peschardt ve Stigsdotter, 2013). Ölçeğin özgün dili İngilizcedir, bununla birlikte ölçek Almanca, İtalyanca ve İspanyolca dillerinde de kullanılmak üzere farklı araştırmacılar tarafından çevrilmiş̧tir (Negrin, HernandezFernaud ve ark., 2017; Rennit ve Maikov, 2015). 
Ülkemizde çevre psikolojisi temellerine dayalı olarak zihinsel restorasyona ilişkin mekânsal kapsamda yapılmış bir çalışmaya alanyazında rastlanmamıştır. Oysa Paker'in (2010) belirttiği gibi çevre psikolojisi yalnızca psikologları ilgilendiren bir alan olmayıp, mimarlık, coğrafya, sosyoloji, ekonomi gibi çok-disiplinli bir yapıdadır ve insan-mekân ilişkisi üzerine çalışan uzmanları yakından ilgilendirir. Kaplan (1983) da algı ve dikkat gibi temel bilişsel süreçleri destekleyen mekânların özelliklerinin incelenmesinin, insan ve fiziksel çevresi arasındaki ilişkinin anlaşılmasını kolaylaştıracağını ifade etmiştir. Bununla birlikte bu tip araştırmalarda verilerin ölçülebilir olması önemlidir. Fiziksel olarak ölçülemeyen bilişsel ve duyusal işlevlerin ölçülmesi ve değerlendirilmesi için kullanılan sistematik araçlar ise psikolojik testler olarak adlandırılmaktadır ve ölçekler bu kapsamda sıklıkla kullanılmaktadır (Urbina, 2004). Bu çalışma kapsamında; kentsel tasarım ve kentsel peyzajın yönetimi çalışmalarında kullanılmak üzere, mekânın algılanan restoratif niteliğinin belirlenmesi amacıyla Hartig ve ark. (1997) tarafindan geliştirilen ARÖ’nün geçerlik ve güvenirlik ölçütlerinin sağlanarak Türkçe'ye uyarlanması hedeflenmiştir.

\section{Materyal ve Metot}

\subsection{Veri Toplama Araçları}

Bu çalışmada Türkçeye uyarlaması yapılmak üzere Hartig ve arkadaşları (1997) tarafından geliştirilen ARÖ’nün 4 alt ölçek (uzaklaşma, büyüleyicilik, kapsam/ahenk ve uyumluluk) ve 26 ifade içeren İngilizce dilindeki özgün metni kullanılmıştır. Uzaklaşma boyutunda 5, büyüleyicilik boyutunda 8 , kapsam boyutunda 4 ve son olarak uyumluluk boyutunda 9 ifade yer almaktadır. İfadeler 7'li Likert tipi $(0=$ hiç katılmıyorum, $6=$ tamamen katıliyorum) puanlama ile derecelendirilmektedir.

Ölçeğin ölçüt geçerliğini belirlemek için Russell ve ekibi (Russell, Weiss ve Mendelsohn, 1989) tarafından geliştirilen ve Aydın ve ekibi (Aydın ve ark., 2011) tarafından Türkçeye uyarlaması yapılmış olan 'Duygu Kafesi Ölçeği' kullanılmıştır. Ölçek, kişinin içinde bulunduğu andaki duygu durumu ve uyarılma düzeyini belirleyen 9x9'luk bir matristen oluşmaktadır.

Veri toplama aracı olarak ölçeğin uygulanmasında, "yüksek, orta ve düşük restoratiflik düzeyleri” göz önünde bulundurularak seçilen ve her bir düzeyi temsilen 3 fotoğrafin bulunduğu 9 adet fotoğraf kullanılmıştır. Daha önce de değinildiği üzere bir mekandaki doğallık düzeyinin gerek dikkat restorasyonu gerekse de çevrenin genel restoratiflik düzeyi ile ilişkili olduğu bilinmektedir (Ulrich ve ark., 1991; Kaplan, 1995). Bu çalışmada da farklı seviyelerde doğallık özelliği gösteren fotoğrafların, farklı restoratif düzeylere sahip olacağı hipotezi benimsenerek fotoğraf seçimi yapılmıştır. $\mathrm{Bu}$ amaçla Çakcı (2007) tarafindan, kent parklarının görsel peyzaj özelliklerinin peyzaj algısı yönünden değerlendirilmesi üzerine yapılmış tez çalışmasından faydalanılmıştır. Söz konusu tez kapsamında, farklı kent parklarına ilişkin görseller bir uzman grubu tarafindan doğallık derecelerine göre sınıflandırılmıştır. Bu doğrultuda yazardan gerekli izinler alınarak, farklı restoratiflik düzeyleri temsil edecek fotoğraflar "doğallık" düzeylerine göre puanlandırılmış kent parklarına ait görüntüler arasından seçilmiştir (Şekil 1).

Alanyazında örneklemin ölçek madde sayısının en az 5-10 katı olması önerilmektedir (Tavşancıl, 2010; Tosun 2018; Yurdugül, 2005). ARÖ'de 26 madde bulunması nedeniyle, hata payı da dikkate alınarak, örneklem sayısı en az 270 kişi olarak belirlenmiştir. Uygulama, 2018-2019 Eğitim- Öğretim yılı, Bahar yarıyılında Ankara Üniversitesi ve Süleyman Demirel Üniversitesi Peyzaj Mimarlığı Bölümlerinde öğrenim gören farklı sınıflardan gönüllü olan 279 lisans öğrencisi (197 kadın, 82 erkek; ortalama yaş= 24) ile gerçekleştirilmiştir.

Uyarlama çalışması için ölçeğin geliştiricilerinden olan Prof.Terry Hartig'den (Uppsala Üniversitesi, İsveç) ve Ankara Üniversitesi Etik Kurul Başkanlığı'ndan (02.01.2019 tarih ve 56786525 sayı) yazılı izin alınmıştır.

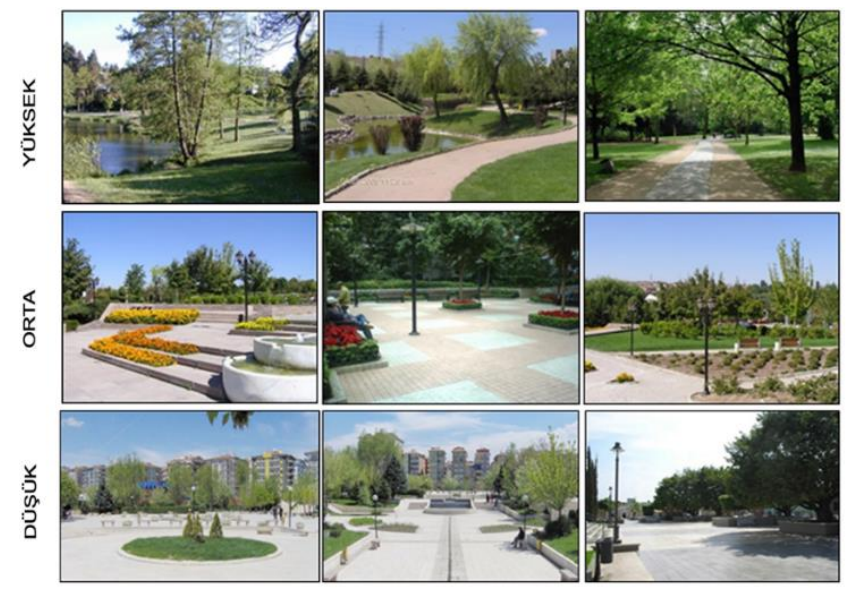

Şekil 1. Restoratiflik Düzeylerine Göre Çalışmada Kullanılan Görseller

\subsection{Metot}

Ölçeğin Türkçeye çevirisinde dil geçerliğini sağlamak amacıyla, Brislin (1970) tarafından kültürlerarası araştırmalar kapsamında önerilen hedef dile çeviri ve kaynak dile geri çeviri süreci uygulanmıştır. Bu süreçte ilk olarak ölçek, ana dili Türkçe olan ve üniversitelerin İngilizce Öğretmenliği Bölümlerinde görev yapan iki akademisyen tarafından, birbirinden bağımsız olarak İngilizceden Türkçeye çevrilmiştir. Bir sonraki aşamada Türkçe ölçek, İngiliz Dili ve Edebiyatı Bölümü'nde görev yapan bir akademisyen tarafından İngilizceye geri çevrilmiştir. İngilizceye geri çevrilen ölçek ile orijinal ölçek karşılaştırılarak, Türkçe tercüme metni üzerinde son düzeltmeler yapılmış ve dil eşdeğerliği sağlanması ile çeviri aşaması son bulmuştur.

Kapsam geçerliğini belirlemek üzere Aiken's V Formulasyonu (Aiken, 1985) temel alınmıştır. Kapsam geçerliğini tespit etmek için uygulanan adımlar sırasıyla; uzman grubunun oluşturulması, uzman değerlendirme formunun hazırlanması, uzman görüşlerinin değerlendirilmesi, ölçek maddelerinin Kapsam Geçerlik İndeksi'nin hesaplanması ve elde edilen verilere göre forma son şeklinin verilmesidir. Çalışmada Peyzaj Mimarlığı Bölümlerinde görev yapan ve rastgele belirlenen 50 akademisyene elektronik ileti yoluyla davet gönderilmiş; 29'u katılmaya gönüllü olmuştur. Uzmanlardan her maddeyi amaca uygunluk ve anlaşılırlık bakımından 1-3 puan (3=uygun, 2=uygun ancak ifade düzeltilmeli, 1=uygun değil) arasında puanlandırmaları ve ifade düzeltmesi önerenlerden ifade önerileri istenmiştir. Yapılan puanlandırmalar SPSS (V.25) yazılımına aktarılarak, her bir maddeye ilişkin Aiken's V Formülasyonu (Aiken, 1985) ile maddenin anlamlılığına ilişkin bir indeks değeri (V) saptanmıştır. V değeri, ölçek maddesinin istatistikî olarak anlamlı olup olmadığını test etmek için geliştirilmiş bir ölçüttür. Bu değer, 0-1 arasında değişmekte olup; 1 'e yakın değerler yüksek kapsam geçerliğini göstermektedir 
(Aiken, 1985). Mevcut çalışmada, Aiken's V indeks tablosuna bakıldığında 29 uzman için indeks değerinin 0.70 ve üzerinde olması maddenin çok iyi kapsam geçerliliği olduğunu göstermektedir.

Kapsam geçerliğinin belirlenmesinden sonra son şekli verilen Türkçe ölçeğin denek grubu tarafindan anlaşılırlığını kontrol etmek amacıyla yapılan pilot çalışma, Ankara Üniversitesi Peyzaj Mimarlı̆̆ Bölümü’nden gönüllü 20 lisans öğrencisi ile gerçekleştirilmiştir. Katılımcılara anlamadıkları ya da duygu durumunu belirtme konusunda rahatsizlık duyabilecekleri herhangi bir sözcük ya da ifade olup olmadığ 1 sorulmuştur.

Görünüş geçerliği sağlandıktan sonra ölçeğin uygulanması aşamasına geçilmiştir. Katılımcılar 31 kişiden oluşan 9 alt gruba ayrılmıştır. Her bir kategoriden (yüksek-orta-düşük restoratiflik derecesi) rastgele seçilen birer fotoğraf projeksiyon cihazı ile yansitılarak katılımcılara gösterilmiştir. Fotoğraf ekrana yansitıldıktan sonra, öğrencilerden kendilerini görseldeki alanın içinde hissetmeye çalışmaları ve orijinal ARÖ'de olduğu gibi 7'li Likert tipi $(0=$ Kesinlikle katılmıorum, $6=$ Kesinlikle katılıyorum) ölçeğin üzerinden değerlendirmeleri istenmiştir.

İkinci aşamada ise ekrandaki fotoğrafa bakıldığında o anlık duygu durumlarını en iyi şekilde ifade ettiğini düşündükleri kutucuğu, Duygu Kafesi Ölçeği üzerinde işaretlemeleri istenmiştir.

$\mathrm{Bu}$ çalışma kapsamında ölçeğin faktör yapısının Türk örnekleminde doğrulanıp doğrulanamayacağının belirlenmesi için Doğrulayıcı Faktör Analizi (DFA) kullanılmıştır. Ölçek geçerliliğini tespit etmek amacıyla DFA kapsamında, Kline (2005) tarafindan önerilen $\chi 2 / s d$, SRMR ( Standardized Root Mean Square Residual), CFI (Comparative Fit Index) ve RMSEA (Root Mean Square Error of Approximation) uyum indeksleri kullanılmıştır. Ölçeğin güvenirliğini belirlemek için ölçeğin bütünü ve alt boyutları kapsamında iç tutarlılığı, Cronbach alfa katsayısı hesaplanarak test edilmiştir. Ölçeğin güvenirliği için katsayı değeri en az .70 olarak kabul edilmiştir (Santos, 1999). Ayrica madde-toplam korelasyonları da incelemiş ve ölçülen nitelik açısından madde-toplam korelasyonu .30 ve daha yüksek olan maddelerin bireyleri "iyi derecede" ayırt ettiği kabul edilmiştir (Büyüköztürk, 2015).

Ölçeğin, farklı restoratiflik düzeyleri arasında ayrım yapıp yapmadığını test etmek için tek yönlü varyans analizi (ANOVA) yapılmıştır. Sonuçların değerlendirilmesinde post-hoc yöntemi olarak Tukey-HSD metodu kullanılmış ve $\% 95$ güven aralığı benimsenmiş̧ir.

Ölçeğin, duygu durumunu ölçen "duygu kafesi” ile uyumunu değerlendirmek için ise korelasyon analizi uygulanmıştır. Korelasyon analizi değerlendirilirken $\mathrm{r}$ değeri anlamlılıkları 0.3-0.5 arası düşük derece, 0.5-0.7 arası orta derece, 0.7-0.9 arası yüksek derece ve 0.9 üzeri çok yüksek derece korelasyonu göstermektedir. 0.3'ün altındaki değerler anlamlı kabul edilmemektedir (Hinkle ve ark., 2003).

\section{Araştırma Sonuçları ve Tartışma}

\section{1. Ölçek Geçerliği ve Güvenirliğine İlişkin Bulgular}

Dil geçerliği çalışması sonucunda çalışmada kullanılan ve Türkçe'ye uyarlanan ARÖ'de yer alan ölçek maddelerinin uzman grubu tarafindan değerlendirilmesinin ardından, verilen puanlara ilişkin Aiken's V Formulasyonu ile belirlenen geçerlik indeks değerleri sonucunda yalnızca 1. ve 14. maddelerde yer alan ifadelerin geçerlik değerleri, sınır değer olarak kabul edilen .70 'in altında saptanmıştır (sırasıyla $\mathrm{V}=0.66, \mathrm{~V}=0.57$ )). Bu maddelere ek olarak 3., 4., 5., ve 18. maddelerdeki ifadeler, V değerleri .70 'in üzerinde olmasına rağmen uzman görüşleri doğrultusunda değiş̧tirilerek ölçeğin son hali Tablo 1'de verilmiştir. Bir ölçeğin farklı bir dile uyarlanması, kültürlerarası anlatım ve kavramlaştırma farklılıkları nedeniyle ölçeğin özünde değişikliklere neden olur (Aksayan ve Gözüm, 2002:11). Bu nedenle çeviri ve geri çeviri aşamasından geçen ölçeğin kapsam geçerliğine ilişkin olarak hesaplanan $\mathrm{V}$ değerleri, bazı ifadeler için kabul edilen sınırın üzerinde olsa da, uzman görüşleri ön plana alınmış ve bu ifadeler öneriler doğrultusunda düzenlenmiştir.

\section{Tablo 1. Türkçe ARÖ}

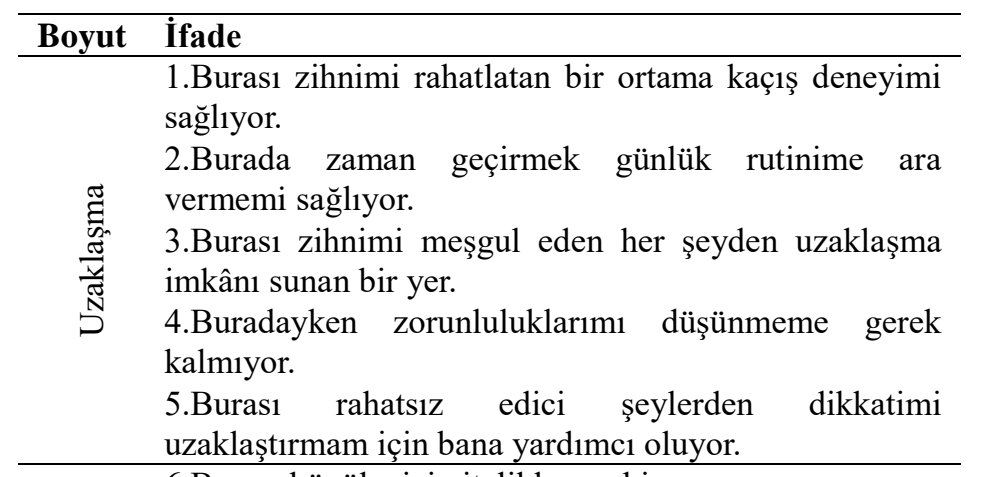

6.Burası büyüleyici niteliklere sahip.

7.Burada dikkatimi çeken/merak uyandıran pek çok ilginç şey var.

8.Burayı daha iyi tanımak istiyorum.

9.Burada incelenecek ve keşfedilecek birçok şey var.

10.Burada etrafi izleyerek daha fazla vakit geçirmek istiyorum.

11.Burası sikıc1 bir yer.

12.Burası ilgi çekici.

13.Burada görülmeye değer bir şey yok.
14.Burada o kadar çok şey oluyor ki zihnim yoruluyor.
15.Burası kafa karıştırıcı bir yer.
16.Burada dikkat dağıtan birçok şey var.
17.Burası kaotik bir yer.
18.Burası kişisel eğilimlerime uyuyor.

19.Burada yapmaktan keyif aldığım şeyleri yapabiliyorum.
20.Buraya ait olduğumu hissediyorum.
22.Burası ile bütünleştiğimi hissediyorum.
23.Burada çevreyi dolaşmaya yardımcı olacak yönlendirici işaretler var.

24.Buranın haritasını zihnimde kolayca oluşturabilirim.

25.Burada yolumu bulmak kolay.

26.Buranın nasıl organize edildiğini anlamak kolay.

Tablo 1'de verilen Türkçe ölçek, görünüş geçerliği çalışmasına katılan öğrencilerin tümü tarafından anlaşılabilir bulunmuş ve ölçeğin uygulanması aşamasına geçilmiştir. Elde edilen verilere uygulanan ilk DFA sonucu, uyum indekslerine ilişkin değerler modelin iyi uyum göstermediğini $[\chi 2(74, \mathrm{~N}=$ $279)=113.36, \quad \chi 2 / \mathrm{sd}=3.56, \quad \mathrm{SRMR}=.085, \quad \mathrm{CFI}=.85$, RMSEA=.09] ortaya koymuştur. $\mathrm{Bu}$ nedenle düzeltme 
(modifikasyon) indeksleri incelenmiştir. Kovaryanslara yönelik düzeltme indeks değeri yüksek olan 4-5, 8-9, 11-13, 24-25 ve 25-26 numaralı ifadelerin hataları arası ilişki olduğu gözlenmiş; buna bağlı olarak aynı boyutların altında yer alan maddeler arasında kovaryans oluşturularak yeni bir model oluşturulmuştur (Şekil 2). Düzeltme indekslerinde ortaya konulan bu hatalar cevaplayanların karakteristik özellikleri gereği ya da maddelerin aynı veya benzer anlamları taşımasından kaynaklanabilir (Yaşlığlu, 2017:79). Ortaya konan ikinci model üzerinden yeniden DFA gerçekleştirilmiş ve elde edilen uyum indeksi değerleri $[\chi 2(293, \mathrm{~N}=279)=1043.43, \chi 2 / \mathrm{sd}=2.59$, $\mathrm{SRMR}=.075, \mathrm{CFI}=.91, \mathrm{RMSEA}=.075]$ Tablo 2'de verilen değerlere göre kabul edilir bulunmuştur. Tablo 3'de ise maddetoplam korelasyonları verilmiştir. Yalnızca 26. Maddenin maddetoplam korelasyon katsayısı .30'dan küçük olarak hesaplanmıştır. Ancak Cronbach alfa iç tutarlılık katsayısı alt boyutlar için .84- .90 arasında (uzaklaşma boyutu=.88, büyüleyicilik boyutu=.90, kapsam boyutu=.89, uyumluluk boyutu=.84) bulunması nedeniyle, ölçeğin özgün yapısının korunması amacıyla bu madde ölçekten çıkarılmamıştır.

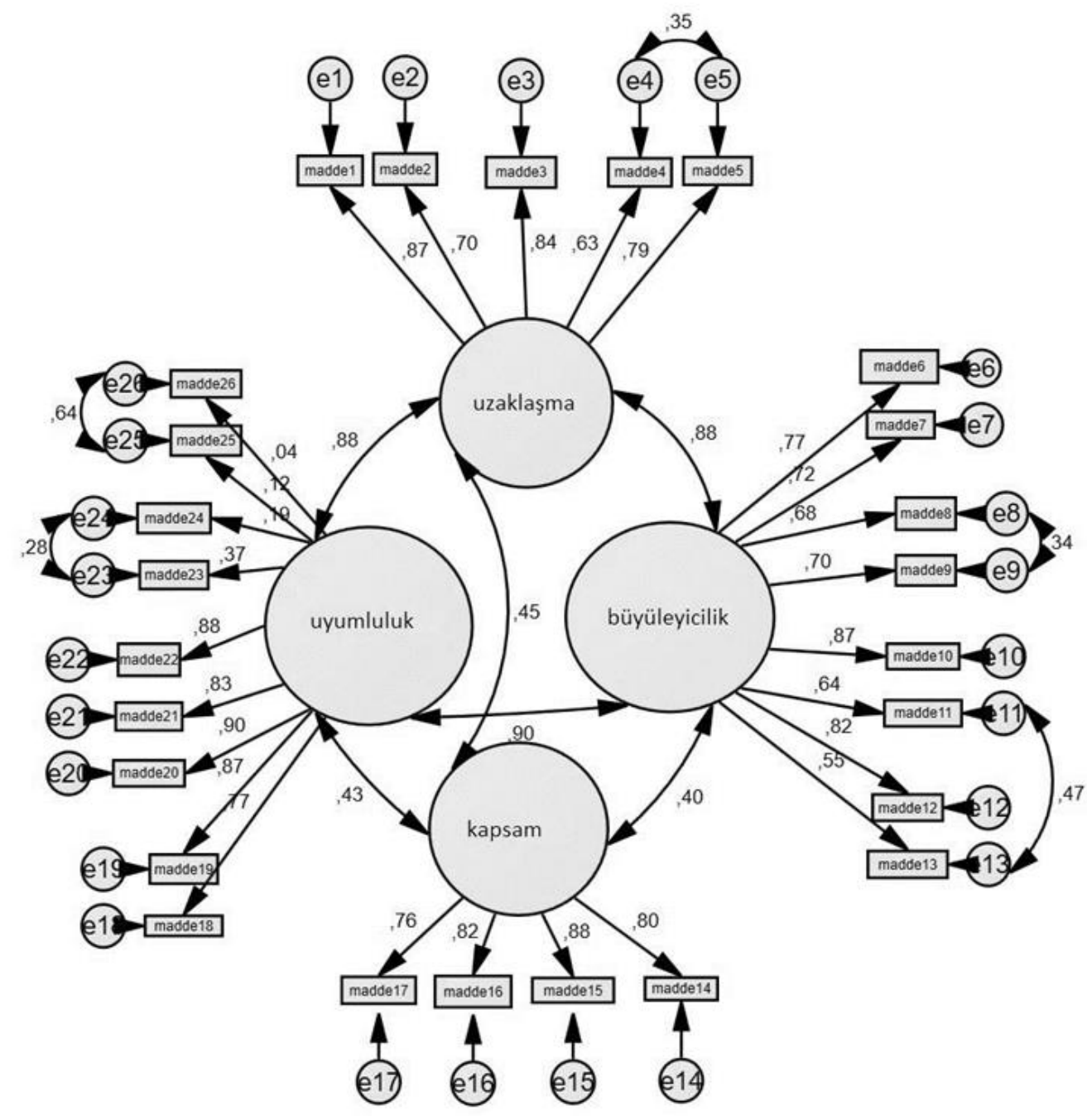

Şekil 2. DFA Yol Şeması

Tablo 2. Düzeltme Sonrası Elde Edilen Uyum Indeksleri ve Kabul Düzeyleri

\begin{tabular}{lcl}
\hline $\begin{array}{l}\text { Uyum } \\
\text { Indeksleri } \\
\chi 2 / s d\end{array}$ & Dĕgerler & Kabul Düzeyi \\
& 2.59 & $\begin{array}{l}\leq 3 \text { mükemmel uyum } \\
\text { (Kline, 2005) } \\
\leq .08 \text { iyi uyum (Jöreskog ve }\end{array}$ \\
SRMR & .075 & $\begin{array}{l}\text { Sörbom, 1993; Kline, 2005) } \\
\geq .90 \text { iyi uyum (Kline, }\end{array}$ \\
CFI & .91 & $\begin{array}{l}2005) \\
\leq .08 \text { iyi uyum (Kline, } \\
\text { 2005) }\end{array}$ \\
RMSEA & .075 & \\
\hline
\end{tabular}

Tablo 3. Ölçek Madde-Toplam Korelasyonları

\begin{tabular}{|c|c|c|}
\hline Boyut & \multicolumn{2}{|c|}{ Madde-toplam korelasyonu } \\
\hline \multirow{5}{*}{ 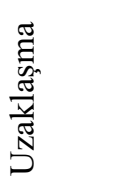 } & Madde 1 & .76 \\
\hline & Madde 2 & .64 \\
\hline & Madde 3 & .80 \\
\hline & Madde 4 & .65 \\
\hline & Madde 5 & .77 \\
\hline \multirow{8}{*}{ 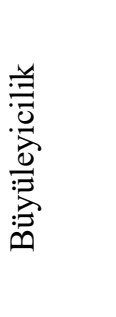 } & Madde 6 & .70 \\
\hline & Madde 7 & .71 \\
\hline & Madde 8 & .67 \\
\hline & Madde 9 & .70 \\
\hline & Madde 10 & .79 \\
\hline & Madde 11 & .62 \\
\hline & Madde 12 & .75 \\
\hline & Madde 13 & .57 \\
\hline
\end{tabular}




\begin{tabular}{|c|c|c|}
\hline \multirow{4}{*}{ 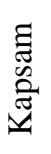 } & Madde 14 & .75 \\
\hline & Madde 15 & .80 \\
\hline & Madde 16 & .75 \\
\hline & Madde 17 & .72 \\
\hline \multirow{9}{*}{ 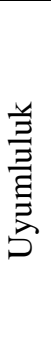 } & Madde 18 & .64 \\
\hline & Madde 19 & .74 \\
\hline & Madde 20 & .70 \\
\hline & Madde 21 & .71 \\
\hline & Madde 22 & .73 \\
\hline & Madde 23 & .43 \\
\hline & Madde24 & .39 \\
\hline & Madde 25 & .34 \\
\hline & Madde26 & .25 \\
\hline
\end{tabular}

\subsection{Restoratiflik Düzeylerine İlişkin Bulgular}

Her ne kadar ölçeğin güvenirlik ve geçerliğinin belirlenmesinde belirleyici olmasa da, ölçeğin uygulandığı görsellere ilişkin algılanan restoratiflik düzeylerine ilişkin tek yönlü ANOVA ve post-hoc analizlerinin sonuçları da çalışma kapsamında irdelenmiştir. Düşük, orta ve yüksek restoratif olarak ayrılan 3 farklı alan arasında ölçeğin; "uzaklaşma" $(\mathrm{F} 2,276=47.12, \quad \mathrm{p}<0.01, \quad \mathrm{k} 1 \mathrm{smi} \quad \eta 2=.25)$, "büyüleyicilik" (F2,276=50.35, $\mathrm{p}<0.01, \quad \mathrm{k} 1 \mathrm{smi} \quad \eta 2=.27)$, "kapsam" (F2,276=23.24, $\quad \mathrm{p}<0.01, \quad \mathrm{k} 1 \mathrm{smi} \quad \eta 2=.14)$ ve "uyumluluk" (F2,276=36.06, $\mathrm{p}<0.01$, k1smi $\eta 2=.21$ ) skorlarında anlamlı fark saptanmıştır. Yapılan post-hoc analiz sonucunda yüksek restoratiflik düzeyine sahip olduğu varsayılan görsellerde tüm boyutlar düşük ve orta restoratif düzeyine sahip görsellere kıyasla anlamlı yüksek çıkarken $(p<0.05)$, düşük ve orta restoratiflik düzeyli görseller arasında "büyüleyicilik" boyutu dışında istatistiksel olarak anlamlı fark saptanamamıştır (Tablo 4). Restoratiflik düzeylerine ilişkin olarak uzaklaşma, uyumluluk ve kapsam boyutlarında düşük ve orta restoratiflik düzeylerinin anlamlı çıkmayışının bu iki restoratiflik düzeyine ait görüntülerin yeteri kadar ayırt edici olmadığından kaynaklandığı düşünülmektedir. Daha önce de belirtildiği gibi, restoratiflik düzeyine ilişkin bulgular ölçeğin geçerliği ve güvenirliği üzerine etki etmeyecek olsa da Türkçe'ye uyarlaması yapılan ölçeğin bundan sonraki uygulamalarında, görüntü seçiminin bulguları etkileyebileceği göz önüne alınmalıdır.

Tablo 4. ARÖ’nün Görsellere Göre Ortalama ve Standart Sapma Değerleri

\begin{tabular}{|c|c|c|c|c|}
\hline \multirow[t]{2}{*}{ Uzaklaşma } & \multirow[t]{2}{*}{$\mathbf{N}$} & \multicolumn{3}{|c|}{ Grup } \\
\hline & & 1 & 2 & \\
\hline Düşük restoratif & 94 & $2,41 \pm 1,45$ & & \\
\hline Orta restoratif & 91 & $2,68 \pm 1,31$ & & \\
\hline Yüksek restoratif & 94 & & $9 \pm 1,02$ & \\
\hline \multirow[t]{2}{*}{ Büyüleyicilik } & \multirow[t]{2}{*}{$\mathbf{N}$} & \multicolumn{3}{|c|}{ Grup } \\
\hline & & 1 & 2 & 3 \\
\hline Düşük restoratif & 94 & $2,24 \pm 1,18$ & & \\
\hline Orta restoratif & 91 & & $5 \pm 1,25$ & \\
\hline Yüksek restoratif & 94 & & & $3,90 \pm 1,10$ \\
\hline \multirow[t]{2}{*}{ Kapsam } & \multirow[t]{2}{*}{$\mathbf{N}$} & \multicolumn{3}{|c|}{ Grup } \\
\hline & & 1 & 2 & \\
\hline Düşük restoratif & 94 & $4,16 \pm 1,52$ & & \\
\hline Orta restoratif & 91 & $4,49 \pm 1,30$ & & \\
\hline Yüksek restoratif & 94 & & $9 \pm 0,95$ & \\
\hline \multirow[t]{2}{*}{ Uyumluluk } & $\mathbf{N}$ & \multicolumn{3}{|c|}{ Grup } \\
\hline & & 1 & 2 & \\
\hline Düşük restoratif & 91 & $2,84 \pm 0,99$ & & \\
\hline Orta restoratif & 94 & $2,80 \pm 1,10$ & & \\
\hline Yüksek restoratif & 94 & & $2 \pm 0,97$ & \\
\hline
\end{tabular}

\subsection{Duygu Kafesi ile Korelasyon Bulguları}

ARÖ ile "duygu kafesi" arasında uyuma bakmak için uygulanan korelasyon analizi sonucunda; uzaklaşma, büyüleyicilik ve kapsam boyutları ile duygu durumu arasında orta derecede pozitif korelasyon saptanmıştır $(\mathrm{r}=.55, \mathrm{r}=.55$ ve $\mathrm{r}=.56, \mathrm{p}<0.01$ ). Uyumluluk ile duygu durumu arasında da düşük derecede pozitif korelasyon saptanmıştır $(\mathrm{r}=.49, \mathrm{p}<0.01)$. ARÖ'nin hiçbir alt boyutu ile uyarılma arasında anlamlı bir korelasyon saptanmamıştır.

\section{Sonuç}

Bu çalışma, özgün dili İngilizce olan ARÖ’yü Türkçe diline uyarlamak amacıyla gerçekleştirilmiştir. Bununla birlikte ölçeğin isminde geçen "restoratif" kelimesini aynı anlam ve orijinal ölçeğin belirlediği hedef kapsamında karşılamak üzere farklı ve
Türkçe kökenli bir ifade önerisi olmamıştır. Ölçek maddelerinin içinde bu kelimenin geçmemesi de göz önüne alınarak, ölçek adında bir değişikliğe gidilmemiştir.

Dil, kapsam ve görünüş geçerliği sağlanan ölçeğe DFA uygulanarak, önceden belirlenen yapının Türkçe dilindeki geçerliği sorgulanmıştır. Düzeltme indekslerinin incelenmesi sonucu aynı faktörlere ait maddeler arasında kovaryans gerçekleştirilerek, modelin $\chi^{2 / \text { sd }}$ açısından mükemmel uyum; SRMR, CFI ve RMSEA indeksleri açısından iyi uyum saptanmıştır. DFA bulguları sonucunda yapı geçerliği sağlanan testin Cronbach alfa iç tutarlılık katsayıları da yüksek düzeyde bulunduğundan, ölçeğin 4 boyutlu yapısının yeterli düzeyde güvenilir olduğu sonucuna ulaşılmıştır. Bununla birlikte çalışmanın kısıtlayıcılarından biri uyarlama çalışmasının lisans öğrencileri ile gerçekleştirilmiş olmasıdır. ARÖ'de kullanılan değişkenler psikolojik değişkenlerdir ve Erkuş (2007)'un da belirttiği üzere bu değişkenler çoğu zaman kültüre bağımlıdır. 
Dolayısıyla aynı kültür içinde farklı hedef gruplara da yapılması önerilmektedir.

1986 y1lında Dünya Sağlık Örgütü tarafindan gerçekleştirilen ilk "Uluslararası Sağlığı Geliştirme Konferansı" sonucunda kabul edilen "Ottawa Bildirgesi"nde; "Sağlık, insanların öğrendikleri, çalıştıkları, oynadıkları ve sevdikleri gündelik yaşam ortamlarında yaratılır ve yaşanır" denmekte, öncelikli eylemler arasında ise "destekleyici çevrelerin yaratılması” yer almaktadır (DSÖ, 1986). Zihinsel sağlık ise üretken bir toplumsal yapı için büyük önem taşır (Gong ve ark., 2016). Bu çalışmada sunulan Türkçeye uyarlanmış ARÖ’nün, mekân ve zihinsel sağlık ilişkisini irdelemeye yönelik bir ölçüm aracı olarak kentsel tasarım araştırmalarına ve pratiğine katkı sağlaması beklenmektedir.

\section{Teșekkür}

Ölçeğin Türkçeye uyarlama iznini veren ve çalışma süresince büyük ölçüde destek veren Prof. Dr. Terry Hartig'e verdiği emek, ayırdığı zaman ve hoşgörüsünden dolayı çok teşekkür eder, saygılarımızı sunarız.

\section{Kaynakça}

Aiken, L. R. (1985). Three coefficients for analyzing the reliability and validity of ratings. Educational and Psychological Measurement, 45, 131-142.

Aksayan, S. \& Gözüm, S. (2002). Kültürlerarası Ölçek Uyarlaması İçin Rehber 1: Ölçek Uyarlama Aşamaları ve Dil Uyarlaması. Hemşirelik Araştırma Dergisi, 4(1), 9-14.

Aydin, A., Araz, A. \& Asan, A. (2011). Görsel Analog Ölçeği ve Duygu Kafesi: Kültürümüze Uyarlama Çalışması. Türk Psikoloji Yazlları, 14 (27), 1-13.

Bai, X., Nath, I., Capon, A., Hasan, N. \& Jaron, D. (2012). Health and wellbeing in the changing urban environment: Complex challenges, scientific responses and the way forward. Current Opinion in Environmental Sustainability, 4, 464-472.

BM, (2018). 2018 Revision of World Urbanization Prospects. (15.02.2020 tarihinde https://www.un.org/development/desa/en/news/population/2 018-revision-of-world-urbanization-prospects.html adresinden alınmıştır.)

Brislin, R.W. (1970). Back-translation for Cross-Cultural Research. Journal of Cross-cultural Pschology, 1(3), 185216.

Büyüköztürk, Ş. (2015). Sosyal Bilimler İçin Veri Analizi El Kitabı (21. Basım). Ankara: Pegem Akademi.

Çakcı, I. (2007). Peyzaj Planlama Çalışmalarında Görsel Peyzaj Değerlendirmesine Yönelik Bir Yöntem Araştırması, Yayınlanmamış doktora tezi, Ankara Üniversitesi Fen Bilimleri Enstitüsü Peyzaj Mimarlığı Anabilim Dalı, Ankara.

DSÖ, 2017. Cities, Urban Planning and Health, Fact Sheet 2. (02.01.2020 tarihinde http://www.euro.who.int/_data/assets/pdf_file/0020/341129 /Fact-Sheet-2-Cities-Urban-planning-and-health.pdf?ua=1 adresinden alınmıştır.)

DSÖ (1986). The Ottawa Charter for Health Promotion. First International Conference on Health Promotion. (23.05.2020 tarihinde https://www.who.int/healthpromotion/conferences/previous/ ottawa/en/index 1.html adresinden alınmıştır.)
Erkuş, A. (2007). Ölçek geliştirme ve uyarlama çalışmalarında karşılaşılan sorunlar. Türk Psikoloji Bülteni, 13(40), 17-25.

French, J.R.P., Rodgers, W.L. \& Cobb, S. (1974). Adjustment as person-environment fit. George V. Coelho, David A. Hamburg \& John E. Adams (Ed.), Coping and Adaptation içinde (316-333).New York: Basic Books.

Gibson, J.J. (1979). The Ecological Approach to Visual Perception. London: Lawrence Erlbaum Associates.

Gong, Y., Palmer, S., Gallacher, J., Marsden, T. \& Fone, D. (2016). A systematic review of the relationship between objective measurements of the urban environment and psychological distress. Environment International, 96, 4857.

Hartig, T., Korpela, K., Evans, G.W. \& Gärling, T. (1997). A measure of restorative quality in environments. Scandinavian Housing \& Planning Research, 14, 175-194.

Hartig, T., Korpela, K. M., Evans, G. W. \& Garling, T. (1996). Validation of a measure of perceived environmental restorativeness. Göteborg Psychological Reports, 26, 7.

Hinkle D.E., Wiersma W. \& Jurs S.G. (2003). Applied Statistics for the Behavioral Sciences (5th Edition). Boston: Houghton Mifflin.

Joye, Y., \& Dewitte, S. (2018). Nature's broken path to restoration: A critical look at Attention Restoration Theory. Journal of Environmental Psychology, 59, 1-8.

Jöreskog, K. G. \& Sörbom, D. (1993). LISREL 8: Structural Equation Modeling with The SIMPLIS Command Language. USA: Lawrence Erlbaum Associates, Inc.

Kaplan, R. (2001). The nature of the view from home. Environment and Behavior, 33(4), 507-542.

Kaplan, R., Kaplan, S. \& Ryan, R. (1998). With People in Mind Design and Management of Everyday Nature. Washington DC: Island Press.

Kaplan, S. (1995). The restorative benefits of nature: toward an integrative framewok. Journal of Environmental Psychology, 15, 169-182.

Kaplan, R. \& Kaplan, S. (1989). The Experience of Nature: A psychological Perspective. New York: Cambridge University Press.

Kaplan, S. (1983). A Model of Person-Environment Compatibility. Environment and Behavior, 15, 311-332.

Kaplan, S. \& Talbot, J.F. (1983). Psychological benefits of a wilderness experience. Irwin Altman \& Joachim F. Wohlwill (Ed.), Behavior and the Natural Environment içinde (163203). New York: Plenum.

Kline, R. B. (2005). Principles and Practice of Structural Equation Modeling (2nd Edition). New York: Guilford Press.

Korpela, K.M., Hartig, T., Kaiser, F.G. \& Fuhrer, U. (2001). Restorative experience and self-regulation in favorite places. Environment and Behavior, 33(4), 572-589.

Negrin, F., Hernandez-Fernaud, E., Hess, S. \& Hernandez, B. (2017). Discrimination of urban spaces with different level of restorativeness based on the original and on a shorter version of Hartig et al.'s Perceived Restorativeness Scale. Frontiers in Psychology, 8, Article 1735.

Ohly, H., White, M.P., Wheeler, B.W., Bether, A. \& Ukoumunne, O.C. (2016). Attention restoration theory: A systematic review of the attention restoration potential of exposure to natural environments. Journal of Toxicology and Environmental Health, Part B, 19(7), 305-343.

Paker, M. (2010). Önsöz. Melek Göregenli, Çevre Psikolojisi, içinde (ix-x). İstanbul: İstanbul Bilgi Üniversitesi Yayınları. 
Parsons, R. (1991). The potential influences of environmental perception on human health. Journal of Environmental Psychology, 11, 1-23.

Pervin, L. A. (1968). Performance and Satisfaction as a function of individual-environment fit. Psychological Bulletin, 69(1), 56-68.

Peschardt, K.K. \& Stigsdotter U.K. (2013). Associations between park characteristics and perceived restorativeness of small public urban green spaces. Landscape and Urban Planning, 112, 26-39.

Renalds, A., Smith, T.H. \& Hale, P.J. (2010). A systematic review of built environment and health. Fam Community Health, 33 (1), 68-78.

Rennit, P. \& Maikov, M. (2015). Perceived restoration scale method turned into (used as the) evaluation tool for parks and open green spaces using Tartu city parks as an example. City, Territory and Architecture, 2, Article 6.

Russell, J. A. Weiss, A. \& Mendelsohn, G. A. (1989). Affect grid: A single-item scale of pleasure and arousal. Journal of Personality and Social Psychology, 57, 493-502.

Santos, J.R.A. (1999). Cronbach's alpha: A tool for assessing the reliability of scales. The Journal of Extension, 37(2), 1-5.

Srinivasan, S., O'Fallon, M.A. \& Dearry, A. (2003). Creating healthy communities, healthy homes, healthy people: Initiating a research agenda on the built environment and public health. American Journal of Public Health, 93(9), 1446-1450.
Tavşancıl, E. (2010). Tutumların Ölçülmesi ve SPSS ile Veri Analizi (4. Baskı). Ankara: Nobel Yayıncılık.

Tosun, H. (2018). Ahlaki Duyarlılık Anketi (ADA): Türkçe geçerlik ve güvenirlik uyarlaması. Journal of Contemporary Medicine, 8(4), 316-321.

Ulrich, R.S., Simons, R.F., Losito, B.D., Fiorito, E., Miles, M.A. \& Zelson, M. (1991). Stress recovery during exposure to natural and urban environments. Journal of Environmental Psychology, 11, 201-230.

Ulrich, R.S. (1984). View through a window may influence recovery from surgery. Science, 244, 420-421.

Ulrich, R.S. (1981). Natural versus urban scenes: some psychophysiological effects. Environment and Behavior, 13, 523-556.

Urbina, S. (2004). Essentials of Psychological Testing. New Jersey: John Wiley \& Sons, Inc.

Yaşlığlu, M.M. (2017). Sosyal bilimlerde faktör analizi ve geçerlilik: keşfedici ve doğrulayıcı faktör analizlerinin kullanılması. Istanbul University Journal of the School of Business, 46, 74-85.

Yurdugül, H. (2005). Ölçek Geliştirme Çalışmalarında Kapsam Geçerliği için Kapsam Geçerlik İndekslerinin Kullanılması. (01.06.2020 tarihinde http://yunus.hacettepe.edu.tr/ yurdugul/3/indir/PamukkaleB ildiri.pdf adresinden alınmıştır.) 